\title{
Critique \\ Integrated analysis environment for the Movement Assessment Battery for Children
}

\author{
Carlos Norberto Fischer \\ Pedro Henrique de Carvalho Teixeira \\ Marcela de Castro Ferracioli \\ Cynthia Yukiko Hiraga \\ Ana Maria Pellegrini \\ São Paulo State University at Rio Claro, Brazil
}

\begin{abstract}
Developmental Coordination Disorder (DCD), a chronic and usually permanent condition found in children, is characterized by motor impairment that interferes with a child's activities of daily living and with academic achievement. One of the most popular tests for the quantitative diagnosis of DCD is the Movement Assessment Battery for Children (MABC). Based on the Battery's standardized scores, it is possible to identify children with typical development, children at risk of developing DCD, and children with DCD. This article describes a computational system we developed to assist with the analysis of results obtained in the MABC test. The tool was developed for the web environment and its database provides integration of MABC data. Thus, researchers around the world can share data and develop collaborative work in the DCD field. In order to help analysis processes, our system provides services for filtering data to show more specific sets of information and present the results in textual, table, and graphic formats, allowing easier and more comprehensive evaluation of the results.
\end{abstract}

Keywords: computational analysis environment, developmental coordination disorder, Movement Assessment Battery for Children

Resumo- "Ambiente de análise integrada para Movement Assessment Battery for Children." O Transtorno do Desenvolvimento da Coordenação (TDC), uma condição crônica e, geralmente, encontrada em crianças, é caracterizado por comprometimento motor que interfere nas atividades de vida diária de uma criança e em seu desempenho acadêmico. Um dos testes mais populares para o diagnóstico quantitativo do TDC é a bateria Movement Assessment Battery for Children (MABC). Com base em escores padronizados da bateria, é possível identificar as crianças com desenvolvimento típico, crianças com risco de desenvolver o TDC e crianças com TDC. Este artigo descreve um sistema computacional que desenvolvemos para ajudar com a análise dos resultados obtidos na bateria MABC. A ferramenta foi desenvolvida para o ambiente web e sua base de dados fornece integração dos dados da MABC. Assim, pesquisadores de todo o mundo podem compartilhar dados e desenvolver trabalho colaborativo na área do TDC. A fim de ajudar os processos de análise, nosso sistema fornece serviços de filtragem de dados para mostrar conjuntos mais específicos de informação e apresentar os resultados em formato de texto, tabela e gráficos, permitindo a avaliação mais fácil e mais abrangente dos resultados.

Palavras-chaves: ambiente de análise computacional, transtorno do desenvolvimento da coordenação, Movement Assessment Battery for Children

Resumen-“Ambiente de análisis integrada para Movement Assessment Battery for Children." Trastorno del Desarrollo de la Coordinación (TDC), una condición permanente crónica y generalment se encuentran en los niños, se caracteriza por alteraciones motoras que interfiere con las actividades de la vida diaria de un niño y con el rendimiento académico. Una de las pruebas más populares para el diagnóstico cuantitativo del TDC es la batería Movement Assessment Battery for Children (MABC). En base a los puntajes estandarizados de la batería, es posible identificar a los niños con un desarrollo típico, los niños en situación de riesgo de desarrollar TDC, y los niños con TDC. En este artículo se describe un sistema computacional que hemos desarrollado para ayudar en el análisis de los resultados obtenidos en la prueba MABC. La herramienta fue desarrollada para el ambiente web y su base de datos proporciona integración de datos MABC. Por lo tanto, los investigadores de todo el mundo pueden compartir datos y desarrollar el trabajo de colaboración en el campo de TDC. Con el fin de ayudar a los procesos de análisis, nuestro sistema ofrece servicios de filtrado de datos para mostrar los conjuntos más específicos de información y presentar los resultados en formatos del texto, tablas y gráficos, lo que permite la evaluación más fácil y más completa de los resultados.

Palabras claves: ambiente de análisis computacional, trastorno de desarrollo de la coordinación, Movement Assessment Battery for Children 


\section{Introduction}

In the course of human development, a child grows in structure and in function, within a complex net of subsystem interactions, into adulthood. Without any apparent reason, some individuals show deviant behavior in one or more aspects of development, which may emerge during childhood (Geuze, 2007). Specifically, developmental coordination disorder (DCD) represents a delay in the development of motor coordination in children, as compared to children of a similar age, leading the child to perform daily activities and tasks--such as tying shoes, writing, using eating utensils, running, or jumping--with difficulty. As a consequence of such difficulties, the child with DCD frequently develops social and emotional problems (Dewey, Kaplan, Crawford, \& Wilson, 2002; Liberman, Ratzon, \& Bart, 2013). Therefore, the identification of this disorder as early as possible is very important, as is the design of a proper intervention, in order to help these children overcome barriers that result from motor coordination difficulties (Missiuna et al., 2011).

For the identification of children with coordination problems, the Movement Assessment Battery for Children (MABC/MABC-2) (Henderson \& Sugden, 1992; Henderson, Sugden, \& Barbett, 2007) has been widely used throughout the world (Missiuna et al., 2011; Smits-Engelsman, Henderson, \& Michels, 1998; Van Waelvelde, De Weerdt, De Cock, \& Smits-Engelsman, 2004). The MABC involves a set of eight tasks, divided into three components (three tasks for manual dexterity, two tasks for ball skills, three tasks for static and dynamic balance). The first version of the MABC (Henderson \& Sugden, 1992) was designed to assess four age ranges (in years): 4 to 6, 7 and 8, 9 and 10, and 11 and 12 . In 2007, a second version of the MABC was released, the MABC-2 (Henderson et al., 2007), expanding the battery's application to a wider age range than the previous version and with three rather than four age ranges (in years): (3 to 6, 7 to 10 , and 11 to 16 ).

The test battery for each age range consists of a combination of quantitative and qualitative motor coordination assessments. All items of the MABC, including the manual, items for test procedures, and assessment forms, are available for purchase from Pearson. The performance of each task in the battery is based on execution time or number of correct executions, which is converted into a score. Based on the sum of the scores from three component tasks, children are categorized as having "typical development," as "at risk of having DCD," and "with DCD" (Henderson \& Sugden, 1992; Henderson et al., 2007).

Regardless of the MABC version, numerous researchers around the world have used the MABC to assess children and to describe motor coordination profiles of the samples (Engel-Yeger, Rosenblum, \& Josman, 2010; Rosblad \& Gard, 1998; Ruiz, Graupera, Gutierrez, \& Miyahara, 2003; SmitsEngelsman et al., 1998; Tsiotra et al., 2006). The characteristics of motor coordination may be associated with developmental patterns of age range and/or gender, culture, and the educational system policies of a specific location or region (Engel-Yeger et al., 2010; Henderson et al., 2007). As a result, a significant amount of data has been produced. These large samples, often comprised of thousands of children, usually are not assessed in one location (school, city, region, or country), and therefore require multi-center studies (Pozamantir, Lee, Chapman, \& Prohovnik, 2010).

Typically, research groups use spreadsheets to store MABC data (scores of each task, scores of components of tasks and child classification) of each assessed child. In many situations, researchers want to store digital photos and other information about the physical and emotional characteristics of a child. Also, after analyzing the generated data, it is important that researchers properly associate the findings and the related literature with a specific battery of tests or to a particular sample (Smits-Engelsman et al., 1998). Furthermore, depending on research objectives, it may be necessary for individual research groups to integrate their data (Ruiz et al., 2003) into the general database. Thus, while it has been a common practice for researchers to store MABC data on spreadsheets, this is not efficient and functional for data retrieval in situations in which a great amount of data in different formats is involved. Additionally, this form of storing data does not provide distant research groups with fast and easy access to locally-stored data.

Therefore, it has become increasingly important for researchers to develop computational environments that can store data in an organized manner, enable the integration of multiple sets of data, and provide tools to help analyze them. Because these tests can be applied to large populations, these resources can allow efficient early intervention. When such tools are made available on the web, multiple users can access them for collaborative work. The construction of these environments should allow consistency not only in studies in our country, but also could enable larger studies, with greater reliability, throughout the entire academic field (Pozamantir et al., 2010).

Within this specific context, the purpose of the present work was to develop the first version of a computational tool, called DCDanalysis, which is capable of managing data analysis in a simpler manner, and of providing professionals with a description of the sample. This will facilitate both data analysis processes and collaborative work between researchers in different locations around the world. Within the DCDanalysis system, data are stored in a structured way to facilitate and accelerate their retrieval. While some existing software components enable and facilitate access to stored data (e.g., spreadsheets), a database management system, the resource used as associated to our system, provides more tools and resources to achieve such goals. DCDanalysis can also provide integration of MABC results obtained in different regions of a country or in different countries, storing them locally into a dedicated system, therefore facilitating the retrieval and subsequent analysis of these data. Thus, several variables such as age, region, and type of MABC task, for example, can be analyzed simultaneously. 


\section{The analysis environment}

DCDanalysis is aimed at helping researchers to analyze results obtained from the MABC. The system integrates data and tools within a dedicated computational environment. The system includes a relational database, which can store and distinguish data from both versions of the battery (MABC and MABC-2) and from different samples.

The DCDanalysis is implemented via a modular approach: data processing and the presentation of results are handled by separate modules. By using a specific system interface, files of newly-assessed MABC results can be submitted in CSV (Comma Separated Values) format. The first module receives this file and imports the data to the system's database. The system then uses a Perl (PERL documentation, 2012) script to process the file and to insert the information into the database's tables. Additionally, data stored in the DCDanalysis's database can be exported to a CSV file, making it possible to use the data with software such as Microsoft Excel, as well as with other common statistical packages (e.g., SPSS and SAS). Thus, researchers can use the data stored in DCDanalysis to run a statistical analysis using other software.

The second module is basically used to present the results stored in the system. These results can be shown in text, table, and graphic formats. In addition, the system offers users several types of filters (using the stored variables) to show more specific information about the results. These filters are implemented through database queries, which are constructed using SQL (Structured Query Language), according to the combination of selected variables, with a relatively high number of possible combinations. Moreover, the filters were developed in such a way that makes the system flexible, allowing users to implement a new filter with the desired variables in a simple and easy manner.

The DCDanalysis has been implemented as a web application using PHP (PHP documentation, 2012) language and the MySQL (MYSQL documentation, 2012) database management system. This means that remote researchers can use the system in a collaborative way. One advantage of storing data in a system based on a database management system like MySQL is that, when a specific filter is not implemented in a given system, the collaborators may develop their own filters and, with permission, query the database remotely. In our case, we allow collaborators to access data stored in DCDanalysis's database.

\section{The system's interfaces}

In addition to results obtained from the MABC, the DCDanalysis's database can store other types of relevant information such as gender, hand dominance, grade, and date of birth, for example. Also, the system allows the researcher to save details he or she collected while administering the MABC, for instance, whether the child refused to perform the task or exhibited other problems.
Moreover, photos of interest, taken during the test, or other type of file (a text file, for instance) can be stored in a system directory and associated with an assessed child. The reference to this file can then easily be retrieved using MySQL, instantly revealing the photo or document. Naturally, the exposure of the participant's photos in the system although in a restricted area access still must have ethical approval.

For the presentation of information stored in the database, DCDanalysis offers several types of user-friendly interfaces. One of these interfaces is related to the filtering process. Figure 1 shows this interface and several fields that can be used to filter data of interest (i.e., Gender, Age, Hand Preference, MD Total, BS Total, Bal Total, Total on the test, Result).

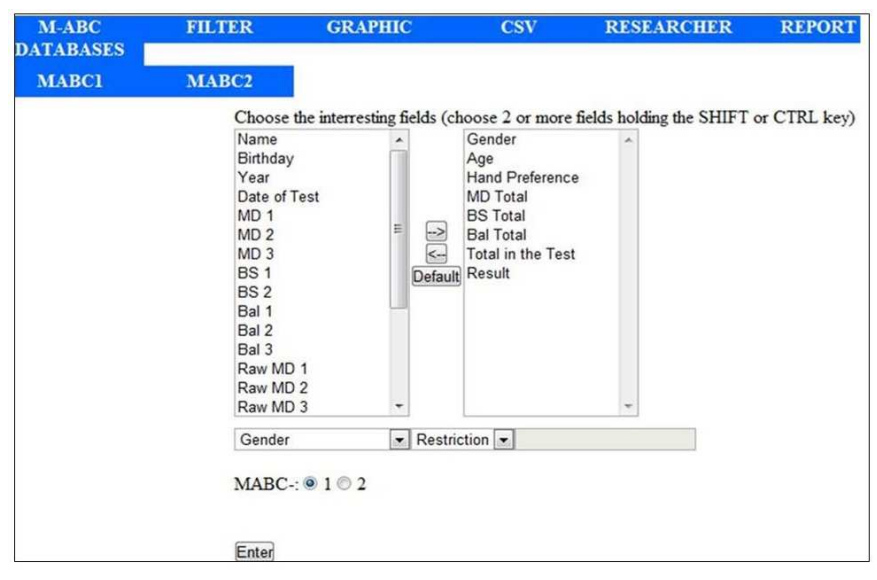

Figure 1. Interface for filtering data of interest. MD=Manual Dexterity; BS=Ball Skills; Bal=Balance

An example of filtered data can be seen in Figure 2, based on the variables selected, as shown in Figure 1. Figure 2 illustrates how information from the database can be reported. In the column called "Total," the results for children with typical development are shown in blue; children at risk of developing DCD are shown in red. For children with DCD, according to the first version of MABC, the general total is represented in pink. Also, it is possible to organize the results according to each field represented in this interface, just by clicking the mouse on the name of the field.

The example of filtered data in Figure 3 shows the results of the MABC, selecting "age group." However, additional filtering could be applied to include, for instance, only "female" and only "left-handed children."

In addition, by clicking the mouse on a particular line in the interface, information about a specific child can be presented (Figure 4). Using this interface, it is possible to modify any information related to the child and to include or delete an observation or a photo. In addition, the user can highlight a specific child in order to refer to him or her easily and quickly, facilitating future searches and analyses. 


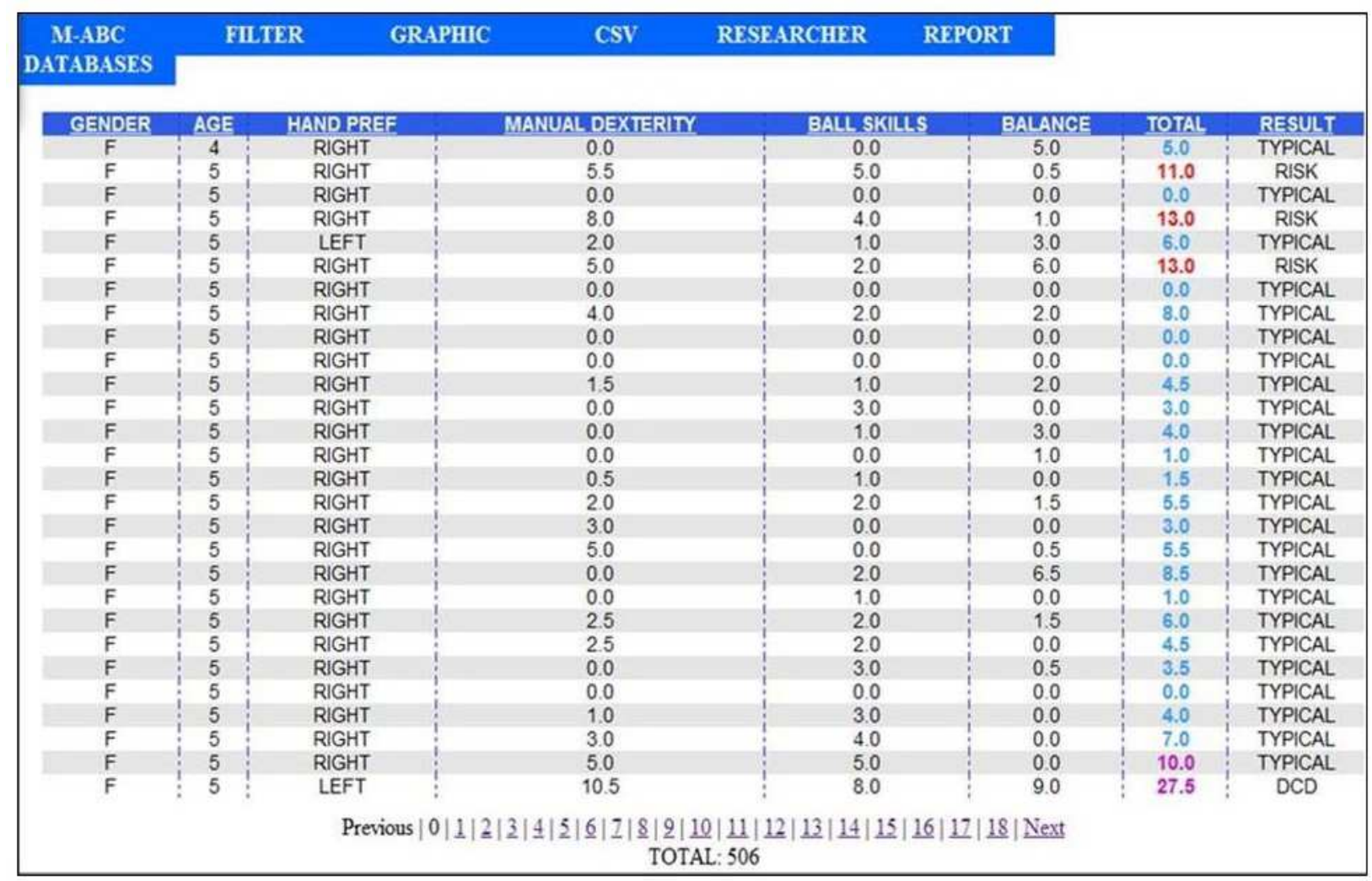

Figure 2. General report on the system's database.

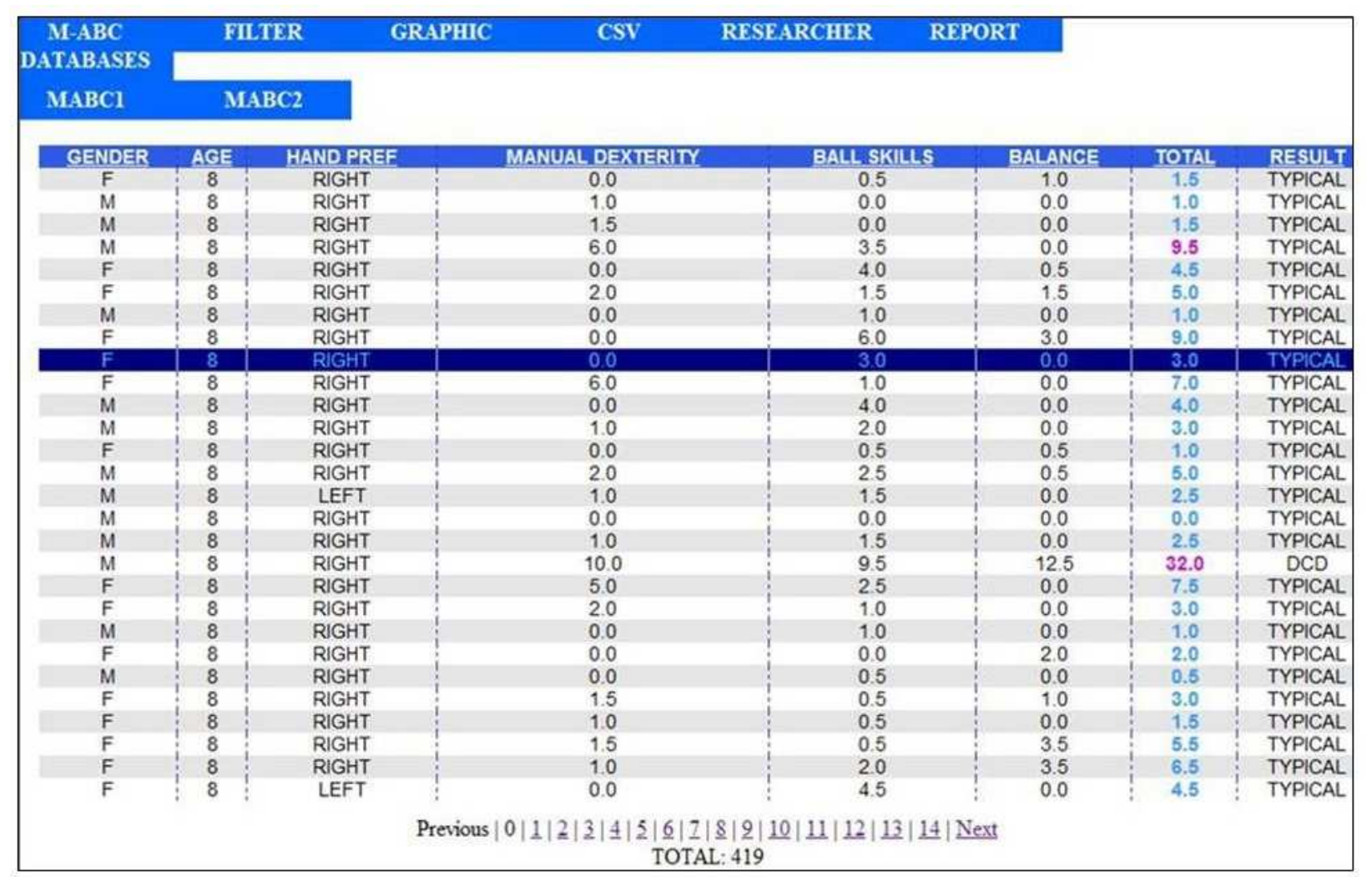

Figure 3. Results of filtering "8-year-old children or older." 


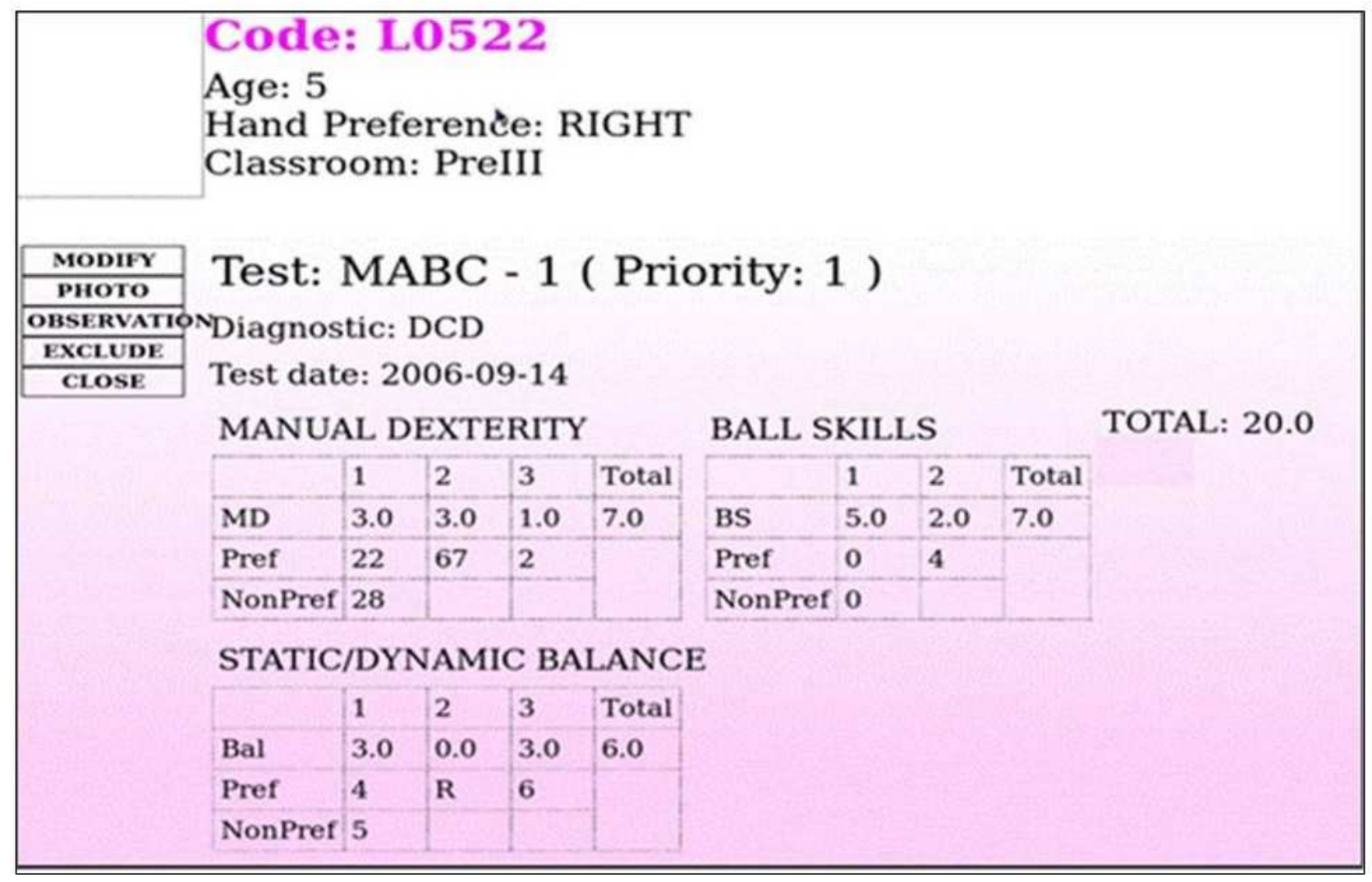

Figure 4. Example of a child's raw data and scores on the MABC.

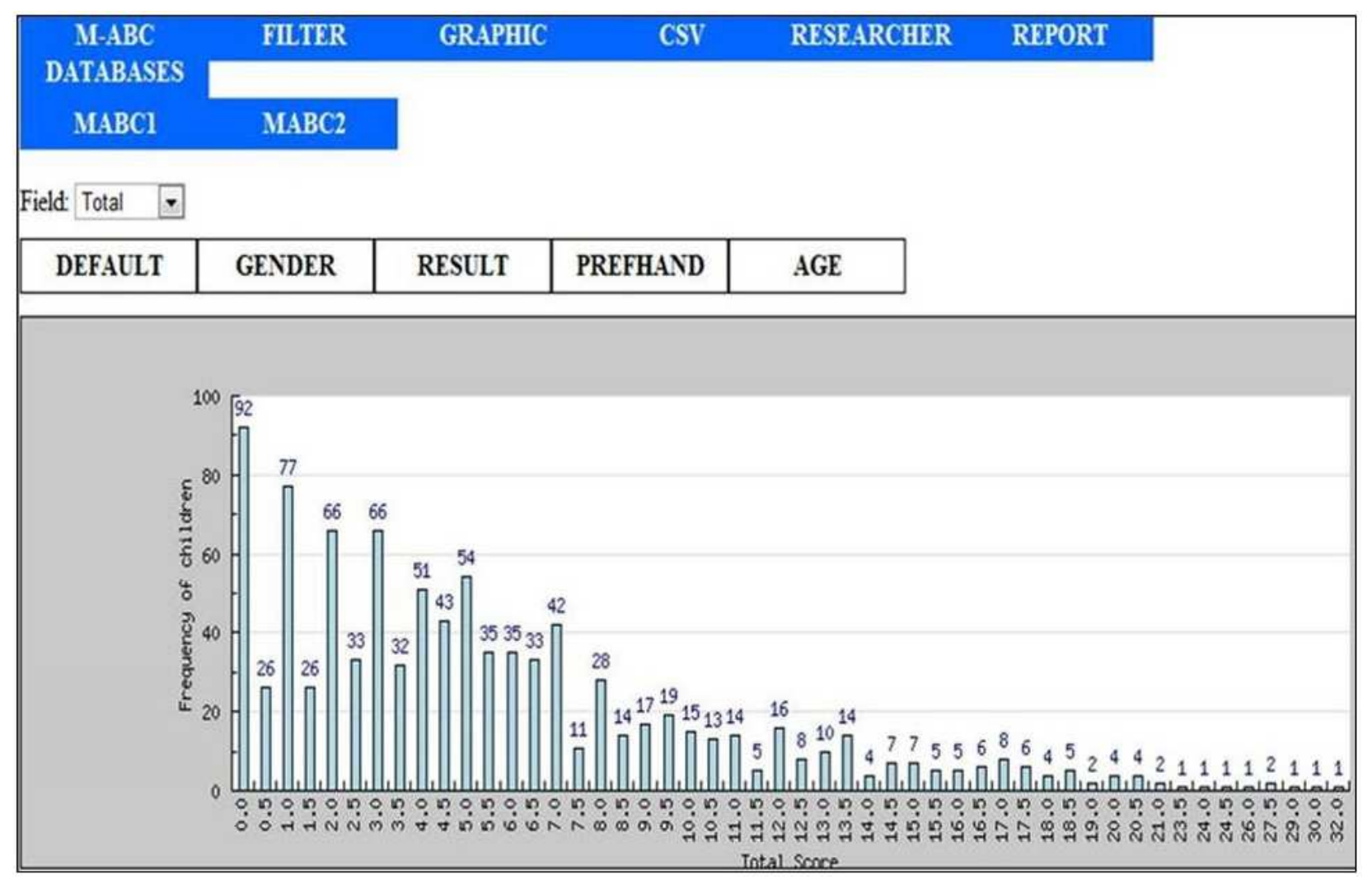

Figure 5. Absolute frequency for children on the MABC total score. 


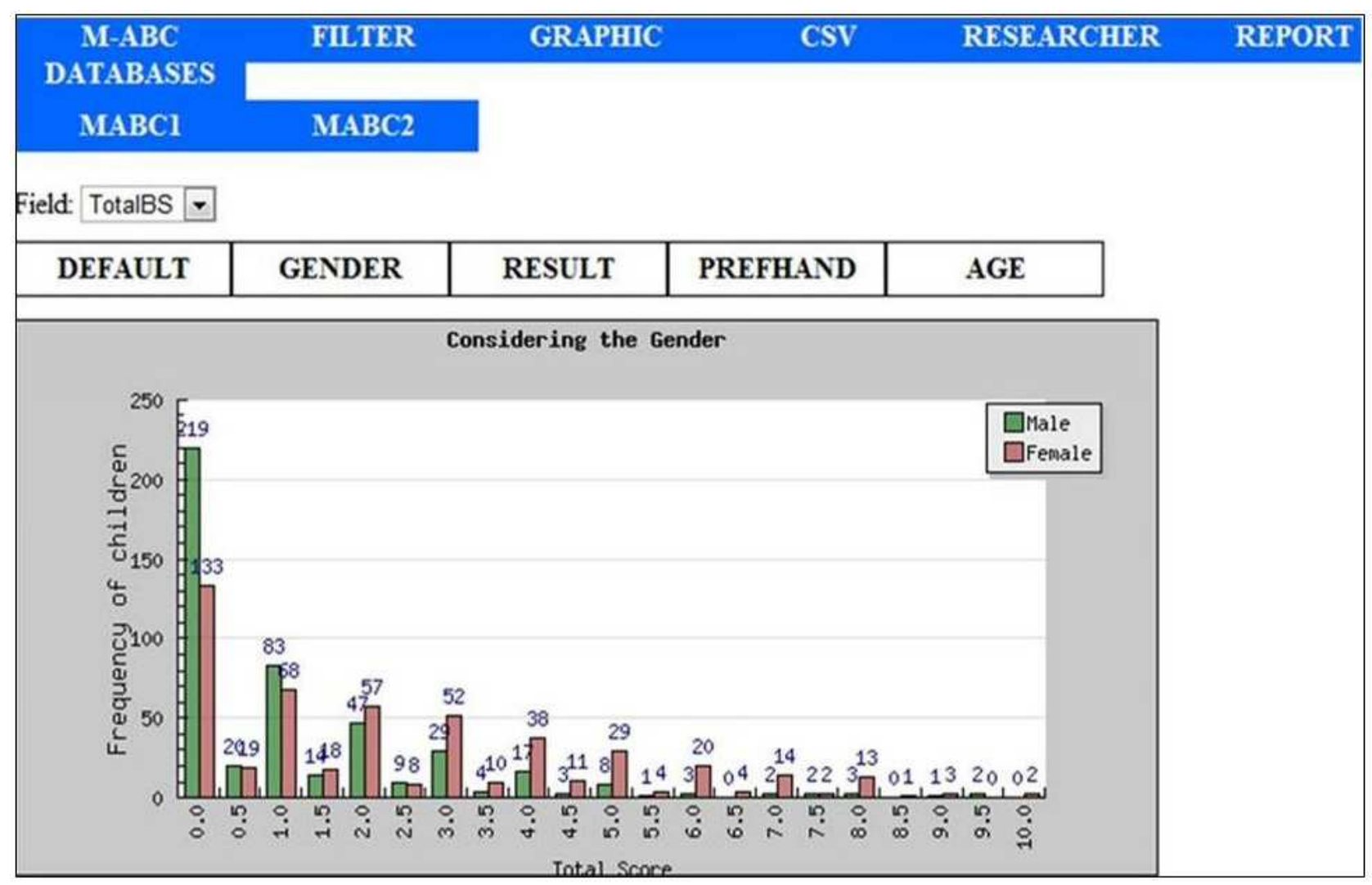

Figure 6. Absolute frequency, as a function of child's ball skill score and age group.

DCDanalysis also allows the construction of dynamic graphics through the JPGraph library of PHP language (JPGRAPH documentation, 2012). Figure 5 is an example of dynamic graphics that can be obtained with DCDanalysis.

It is also possible to display absolute frequencies for children on a partial MABC score, separated by component (i.e., manual dexterity, ball skills, or balance), by gender, by preferred hand, and/or by age group. Figure 6 shows absolute frequency for children on the ball skills score, separated by gender.

Figure 7 depicts a general report, as well as total and partial frequencies, according to classification of MABC results (Version 1), gender, and age group.

\section{Data analyses using the DCDanalysis System}

The main purpose of the DCDanalysis system is to provide researchers with a tool for the analysis of a large amount of data from MABC as it relates to a specific population. Filters and graphics were implemented to reach this objective. Such analyses can contribute for the identification of either the main characteristics of a particular population in terms of gender, age, and specific aspect of behavior as they relate to the components of the MABC or some particular characteristic of a child.

In order to evaluate whether the system reached this objective, it was tested using information about 1,000 children,
4-10 years old, who had been assessed via the MABC (Version 1) (Henderson \& Sugden, 1992). The procedures for assessment via the MABC were approved by the Ethics Committee of the University. The system helped reveal some interesting features about the stored data. For instance, the system's filters made it possible to identify children with

\begin{tabular}{|c|c|c|c|c|}
\hline $\begin{array}{c}\text { M-ABC } \\
\text { DATABASESS }\end{array}$ & FLLTRR & GRAPHIC & CSV & RRSBARCHRR \\
\hline MABCl & MABC2 & & & \\
\hline
\end{tabular}

\section{General Report}

Total of Evaluated Chidren: 973

Total of Nomal Chideren: 802

Total of Childen at Risk 83

Total of Children with DCD: 88

Total of Male Childeren 467

Total of Female Chidren 506

Total of Childeren in Ist Age Group: 323

Total of Children in 2nd Age Group: 379

Total of Children in 3rd Age Group: 271

Figure 7. General report for total and partial absolute frequency of the sample according to motor coordination, gender, and age group. 
Table 1. Examples of a DCD child with score equal to zero in the Manual Dexterity component (MD-Tasks 1, 2, and 3), five DCD children with scores equal to zero in the Ball Skills component (BS-Tasks 1 and 2), and four DCD children with scores equal to zero in the Balance component (BAL-Tasks 1, 2, and 3).

\begin{tabular}{ccccccccccc}
\hline \hline ChildCode & Age & MD1 & MD2 & MD3 & BS1 & BS2 & BAL1 & BAL2 & BAL3 & RESULT \\
\hline L0032 & 8 & 0 & 0 & 0 & 5 & 4 & 3 & 0 & 3 & DCD \\
L0193 & 7 & 0,5 & 4 & 5 & 0 & 0 & 0 & 4 & 0 & DCD \\
L0249 & 9 & 3 & 4 & 5 & 0 & 0 & 2,5 & 0 & 0 & DCD \\
L0334 & 9 & 3 & 4 & 5 & 0 & 0 & 0 & 1,5 & 0 & DCD \\
L0415 & 9 & 1,5 & 1 & 5 & 0 & 0 & 3 & 3 & 2 & DCD \\
L0626 & 10 & 2,5 & 5 & 5 & 0 & 0 & 5 & 0 & 0 & DCD \\
L0196 & 7 & 2 & 5 & 2 & 0,5 & 4 & 0 & 0 & 0 & DCD \\
L0379 & 10 & 0,5 & 0 & 5 & 4 & 4 & 0 & 0 & 0 & DCD \\
L0400 & 10 & 0 & 5 & 5 & 5 & 0 & 0 & 0 & 0 & DCD \\
L0441 & 10 & 4 & 5 & 0 & 1 & 4 & 0 & 0 & 0 & DCD \\
\hline \hline
\end{tabular}

DCD, even though their MABC scores equaled zero in one of the three task components. Table 1 shows example of children with scores equal to zero for all types of task categories but who obtained high scores in other categories and, hence, they were identified as children with DCD.

The system also allowed the identification of the components of the test that children with DCD, or those at risk of developing DCD, had more difficulties performing, and, as a consequence, they had the worst scores. For the 88 children identified with DCD, about $57 \%$ presented the worst scores in Manual Dexterity, 21\% in Balance, and 14\% in Ball Skills. It seems interesting to note that $8 \%$ of them showed the worst results in two components of the battery. Of the 84 children at risk of developing DCD, $57 \%$ presented high scores in Manual Dexterity, 25\% in Ball Skills, and 14\% in Balance. About $4 \%$ of them showed the worst results in two components of the Battery. From this analysis, we can infer that the Manual Dexterity component was the most influential component in the identification of children with DCD, or those at risk of developing DCD, in this sample.

Although additional analyses are needed in order to identify trends in the data or commonalities in the sample that could be related, for example, to the children's geographical regions and/or cultures, the resources provided by the DCDanalysis proved to be interesting and useful ones for analyses of data obtained using MABC. To the best of our knowledge, the present work is the first to propose a system specifically related to MABC data and its related variables, in which basic functions can be utilized to provide a general overview.

An important feature of the system is its ability to facilitate collaborative work between research groups from different locations. A test version of the system, which uses a fictitious data set, is publicly available at http:// gbirc.rc.unesp.br/mabc/demo/. The actual data stored in the DCDanalysis's database, and access to its input data, are not publicly available, as privacy demands require that access to the stored data be limited to registered researchers with access via password. The DCDanalysis system can be obtained under request to its creators and interested collaborators should contact the authors.

\section{Conclusion}

An important contribution of the DCDanalysis system is that it allows researchers from different geographical areas and cultures to have access to this comprehensive database and to include their own data, creating a collective, continuously-emerging database. Additionally, through its ability to store large amounts of data and to filter information, the system facilitates analyses not formerly available to users of the MABC. This collective enterprise has the potential to improve the power of knowledge gathered worldwide by researchers in the field of motor coordination.

\section{References}

Dewey, D., Kaplan, B. J., Crawford, S. G., \& Wilson, B. N. (2002). Developmental coordination disorder: associated problems in attention, learning, and psychosocial adjustment. Human Movement Sciences, 21(5-6), 905-918. doi: http:// www.ncbi.nlm.nih.gov/pubmed/12620725

Engel-Yeger, B., Rosenblum, S., \& Josman, N. (2010). Movement assessment battery for children (M-ABC): establishing construct validity for Israeli children. Research in Developmental Disabilities, 31(1), 87-96. doi: 10.1016/ 
j.ridd.2009.08.001

Geuze, R. H. (2007). Characteristics of DCD: on problems and prognosis. In R. H. Geuze (Ed.), Developmental coordination disorder: a review of current approaches. France, Marseille: Solal.

Henderson, S. E., \& Sugden, D. A. (1992). The movement assessment battery for children. London: Psychological Corporation.

Henderson, S. E., Sugden, D. A., \& Barbett, A. L. (2007). The movement assessment battery for children-2. London: Harcourt Assessment.

JPGRAPH documentation. (2012). Retrieved January 20, 2012 from doi:http://jpgraph.net/

Liberman, L., Ratzon, N., \& Bart, O. (2013). The profile of performance skills and emotional factors in the context of participation among young children with Developmental Coordination Disorder. Research in Developmental Disabilities, 34(1), 87-94. doi: http://dx.doi.org/10.1016/j.ridd.2012.07.019

Missiuna, C., Cairney, J., Pollock, N., Russell, D., Macdonald, K., Cousins, M., \& Schmidt, L. (2011). A staged approach for identifying children with developmental coordination disorder from the population. Research in Developmental Disabilities, 32(2), 549-559. doi: http://dx.doi.org/10.1016/j.ridd.2010.12.025

MYSQL documentation. (2012). Retrieved February 15, 2012 from doi:http://dev.mysql.com/doc/

PERL documentation. (2012). Retrieved February 15, 2012 from doi:http://www.perl.org/docs.html

PHP documentation. (2012). Retrieved February 15, 2012 from doi:http://www.php.net/docs.php

Pozamantir, A., Lee, H., Chapman, J., \& Prohovnik, I. (2010). Web-based Multi-center Data Management System for Clinical Neuroscience Research. Journal of Medical Systems, 34(1), 25-33. doi: 10.1007/s10916-008-9212-2

Rosblad, B., \& Gard, L. (1998). The assessment of children with developmental coordination disorders in sweden: a preliminary investigation of the suitability of the movement ABC. Human Movement Sciences, 17(4-5), 711-719. doi: <Go to ISI>:// 000075788900013

Ruiz, L. M., Graupera, J. L., Gutierrez, M., \& Miyahara, M. (2003). The assessment of motor coordination in children with the movement $\mathrm{ABC}$ test: a comparative study among japan, usa and spain. International Journal of Applied Sports Sciences, 15(1), 22-35. doi: http://www.cafyd.com/ruizlass2003.pdf

Smits-Engelsman, B. C. M., Henderson, S. E., \& Michels, C. G. J. (1998). The assessment of children with Developmental Coordination Disorders in the Netherlands: The relationship between the Movement Assessment Battery for Children and the Korperkoordinations Test fur Kinder. Human Movement Sciences, 17(4-5), 699-709. doi: <Go to ISI >:// 000075788900012

Tsiotra, G. D., Flouris, A. D., Koutedakis, Y., Faught, B. E., Nevill, A. M., Lane, A. M., \& Skenteris, N. (2006). A comparison of developmental coordination disorder prevalence rates in Canadian and Greek children. Journal of Adolescent Health, 39(1), 125-127. doi: DOI 10.1016/j.jadohealth.2005.07.011

Van Waelvelde, H., De Weerdt, W., De Cock, P., \& SmitsEngelsman, B. C. M. (2004). Aspects of the validity of the movement assessment battery for children. Human Movement Sciences, 23(1), 49-60. doi: DOI 10.1016/j.humov.2004.04.004

\section{Authors' note}

Carlos Norberto Fischer (carlos@rc.unesp.br) and Pedro Henrique de Carvalho Teixeira (pedrohtex@yahoo.com.br) are with the Statistics, Applied Mathematics, and Computer Science Department of the Institute of Geosciences, São Paulo State University (UNESP), Rio Claro, SP, Brazil

Marcela de Castro Ferracioli (mcf@rc.unesp.br), Cynthia Yukiko Hiraga (cyhiraga@ rc.unesp.br) and Ana Maria Pellegrini (anapell@rc.unesp.br) are with the Physical Education Department, Institute of Biosciences, São Paulo State University (UNESP), Rio Claro, SP, Brazil

\section{Correspondence to:}

Carlos Norberto Fischer

Address: Av. 24A, 1515, Statistics, Applied Mathematics, and Computer Science Department, IGCE, Rio Claro, SP, Brazil

Zipcode: 13506-900

Telephone: +55 (19) 35269089

E-mail: carlos@rc.unesp.br

Manuscript received on July 7, 2012

Manuscript accepted on June 6, 2013

Motriz. Journal of Physical Education. UNESP, Rio Claro, SP, Brazil, eISSN: 1980-6574, is licenced under a Creative Commons License, Version 3.0. 